\title{
Estimativas de biomassa aérea e volume lenhoso de Sabiá (Mimosa caesalpiniifolia Benth.) em povoamento com 12 anos de idade
}

\author{
Marcelo Silva de Lucena ${ }^{1 \star(D)}$, Erick Daniel Gomes da Silva² (D), Allyson Rocha Alves² (D), Alan Cauê \\ de Holanda ${ }^{3}$ (D), Romário Mendes Bezerra ${ }^{2}$ (D), Rafael Rodolfo de Melo 4 (D)

\footnotetext{
${ }^{1}$ Departamento de Ciência Florestal, Programa de Pós-graduação em Ciência Florestal, Universidade Estadual Paulista “Júlio de Mesquita Filho". Fazenda Lageado, Avenida Universitária, 3780, Altos do Paraíso - Botucatu/SP, $18610-034$.

${ }^{2}$ Universidade Federal Rural do Semi-Árido, UFERSA, Rua Francisco Mota Bairro, 572 - Pres. Costa e Silva, Mossoró RN, 59625-900.

${ }^{3}$ Departamento de Ciências Vegetais, Escola Superior de Agricultura de Mossoró, Universidade Federal Rural do SemiÁrido - Pres. Costa e Silva, Mossoró - RN, 59625-900.

${ }^{4}$ Programa de Pós-Graduação em Ciências Florestais e Ambientais, Universidade Federal de Mato Grosso - Campus Cuiabá. Av. Fernando Corrêa da Costa, nº 2367 - Bairro Boa Esperança, Cuiabá-MT, Brasil - 78060-900.

* Autor para correspondência: marceloslucenarn@gmail.com
}

Recebido em 31 de julho de 2019.

Aceito em 22 de setembro de 2020.

Publicado em 31 de setembro de 2020.

Resumo - Modelos matemáticos produzidos a partir de relações dendrométricas que usam o diâmetro à altura do peito (DAP) e a altura podem ser uma alternativa para estimar a biomassa e o volume lenhoso de indivíduos e de povoamentos florestais, sendo útil na gestão florestal. Assim, objetivamos ajustar modelos matemáticos para estimar a biomassa aérea úmida e o volume lenhoso de um povoamento de Sabiá. Para isso, fizemos a cubagem da biomassa aérea úmida e do volume à altura comercial e total. Utilizamos o DAP e as alturas como variáveis preditoras, conforme as exigências de cada modelo. A escolha do melhor modelo foi baseada no $\mathrm{R}^{2}$ ajustado, na normalidade dos resíduos, na sua distribuição gráfica e no erro-padrão da estimativa (Syx\%). O modelo Biomassa $=7,134411743986+0,218501385492548^{\star} \mathrm{DAP}^{2}$ foi o mais adequado aos dados ajustados.. Os modelos que forneceram os melhores ajustes para estimar o volume à altura comercial e altura total foram, respectivamente: $\mathrm{V}=0,0042493278498619+0,0000322813042346465^{\star}\left(\mathrm{DAP}^{2 \star} \mathrm{Hcomercial} \mathrm{e}\right.$ $\mathrm{V}=0,00404929514539746+0,0000278267926885885^{\star}\left(\mathrm{DAP}^{2 \star}\right.$ Htotal $)$. A altura foi uma variável que contribuiu para a melhoria dos modelos para estimar o volume, enquanto não produziu melhorias nos modelos para estimar a biomassa aérea úmida.

Palavras-chave: Manejo Florestal. Silvicultura. Semiárido Brasileiro. Equações Alométricas. Modelos Matemáticos.

\section{Estimates of aboveground biomass and wood volume in Sabiá (Mimosa caesalpiniifolia Benth.) stands}

Abstract - Mathematical models produced from dendrometric relationships that use the diameter at breast height $(\mathrm{DBH})$ and height can be an alternative to estimate the biomass and wood volume of individuals and forest stands, which is useful for forest management. Thus, we aim to adjust mathematical models to estimate the humid aerial biomass and the wood volume of a Sabiá stand. 
To do this, we made the cubage of the humid aboveground biomass and the volume at commercial and total height. We used $\mathrm{DBH}$ and height as predictor variables, according to the requirements of each equation. The choice of the best equation was based on adjusted $\mathrm{R}^{2}$, on the normality of the residues, on their graphical distribution and on the standard error of the estimate (Syx\%). The biomass model $=7.134411743986+0.218501385492548{ }^{\star} \mathrm{DAP}^{2}$ was the most suitable for the adjusted biomass data. The best equations for estimating the volume at commercial height and total height were respectively: $\mathrm{V}=0.0042493278498619+0.0000322813042346465^{\star}\left(\mathrm{DAP}^{2 \star}\right.$ Hcommercial $)$ and $\mathrm{V}=0.00404929514539746+0.0000278267926885885^{\star}\left(\mathrm{DAP}^{2 \star} \mathrm{Htotal}\right)$. The height was a variable that contributed to the improvement of the models to estimate the volume, however, it did not produce improvements in the models to estimate humid aerial biomass.

Key-words: Forest Management. Silviculture. Brazilian Semiarid. Allometric Equations. Mathematical Models.

\section{Estimacionesdebiomasaaéreayvolumenleñosodel “Sabiá”(Mimosacaesalpiniifolia Benth.) en una población con 12 años}

Resumen - Los modelos matemáticos producidos a partir de relaciones dendrométricas que utilizan el diámetro a la altura del pecho (DAP) y la altura son una alternativa para estimar la biomasa y el volumen leñoso de individuos y poblaciones forestales, y son útiles en el manejo forestal. Así, pretendemos ajustar modelos matemáticos para estimar la biomasa aérea húmeda y el volumen leñoso de una población de "Sabiá". Para ello, hicimos la cubicación de la biomasa aérea húmeda y el volumen a la altura comercial y total. Utilizamos DAP y las alturas como variables predictoras, de acuerdo con los requisitos de cada modelo. La elección del mejor modelo se basó en el $\mathrm{R}^{2}$ ajustado, en la normalidad de los residuos, en su distribución gráfica y en el error estándar de la estimación $\left(\right.$ Syx\%). El modelo Biomasa $=7,134411743986+0,218501385492548 *$ DAP $^{2}$ fue el más adecuado para los datos ajustados. Los mejores modelos para estimar el volumen en las dos alturas evaluadas fueron, respectivamente: $\mathrm{V}=0,0042493278498619+0,0000322813042346465^{\star}\left(\mathrm{DAP}^{2 \star}\right.$ Hcomercial $)$ y V $=0,00404929514539746+0,0000278267926885885^{\star}\left(\mathrm{DAP}^{2 \star}\right.$ Htotal $)$. La altura fue una variable que contribuyó a la mejora de los modelos para estimar el volumen, mientras no produjo mejoras en los modelos para estimar la biomasa aérea.

Palabras-clave: Manejo Forestal. Silvicultura. Semiárido Brasileño. Ecuaciones Alométricas. Modelos Matemáticos.

\section{Introdução}

A determinação da biomassa aérea e do volume lenhoso da vegetação é uma importante informação biológica, já que ela pode ser relacionada, principalmente, à produção lenhosa, à produtividade primária liquida, ou ser um indicador do desempenho de crescimento de uma espécie em um sítio específico. Além disso, o correto manejo das espécies de interesse econômico requer meios adequados para estimar o volume e a biomassa acima do solo, o que contribui para que a tomada de decisão do manejo florestal seja mais precisa (Sampaio e Silva 2005; Thomas et al. 2006; Barros et al. 2010; Sampaio et al. 2010; Souza et al. 2016; Dalla Lana et al. 2018).

Para estimar a biomassa e o volume há, basicamente, duas metodologias que podem ser utilizadas: métodos diretos e indiretos. Os métodos diretos visam determinar a biomassa e o volume em uma 
área por meio da corte, medição e da cubagem de todos os indivíduos. Devido às complicações práticas e econômicas desse método, as estimativas por meios indiretos são empregados. Estes utilizam modelos estatísticos, como as equações alométricas, para, por meio de amostras de volume e biomassa determinados em parte do povoamento, produzir modelos que tenham boa capacidade preditiva (Silva 2005; Thomas et al. 2006; Soares et al. 2011; Brianezi et al. 2013; Souza et al. 2016).

Noâmbito das ciências florestais, equações alométricas sãoentendidos como modelos matemáticos baseados em regressão estatística que utilizam dados de biomassa ou volume lenhoso obtidos em experimentos de campo, onde as árvores são colhidas, pesadas ou cubadas. Estas informações são utilizadas para obter coeficientes que ajustam os valores das medidas de peso ou volume cubados a algum atributo dendrométrico (tal como DAP, altura, densidade da madeira, etc), com a finalidade de produzir um modelo matemático com poder preditor estatisticamente satisfatório (Chave et al. 2005; Sampaio et al. 2010; De Lima et al. 2017).

O emprego desses modelos matemáticos, cujo uso operacional dispensa realizar procedimentos operacionais muito dispendiosos, como nos métodos diretos, permite o conhecimento da biomassa e do volume de indivíduos ou povoamentos florestais, o que é indispensável ao adequado manejo das espécies florestais com interesse comercial, podendo ajudar aos profissionais e tomadores de decisão a obter estimativas rápidas, com precisão aceitável e de fácil obtenção.

Entretanto, embora a determinação da biomassa aérea e do volume de espécies arbóreoarbustivas da Caatinga já tenha sido abordada em outros trabalhos (Silva e Sampaio 2008; Sampaio et al. 2010; De Lima et al. 2017; Barreto et al. 2018; Dalla Lana et al. 2018), as pesquisas que visam estudar esses parâmetros em plantios homogêneos e, especificamente, com povoamentos de Mimosa caesalpiniifolia Benth (Sabiá) são pouco comuns, ainda mais quando se considera condições particulares de cada sítio e a necessidade de ajustes específicos aos dados locais, para incidir em menor erro nas estimativas.

Essa é uma espécie nativa da Caatinga com potencial comercial, rápido crescimento em locais propícios, cujos indivíduos podem atingir $10 \mathrm{~m}$ de altura e $40 \mathrm{~cm}$ de DAP. Sua madeira apresenta alta durabilidade em condições de campo e uma diversidade de usos, como caibros e ripas, além de possuir um bom potencial energético (Barros et al. 2010; Alencar 2011; Maia 2012).

Assim, o objetivo desse trabalho foi obter modelos matemáticos para estimar a biomassa acima do solo úmida e o volume lenhoso de indivíduos da espécie Sabiá, Mimosa caesalpiniifolia Benth., em um povoamento com 12 anos de idade no semiárido do Rio Grande do Norte, Brasil.

\section{Material e métodos}

\section{Localização e características do povoamento}

O trabalho foi realizado em um povoamento florestal de Mimosa caesalpiniifolia Benth. com 12 anos de idade, implantado na Fazenda Baixa da Oiticica, localizada a $30 \mathrm{~km}$ da sede do município de Mossoró, Rio Grande do Norte, localizado sob as coordenadas 5²9’57.1” S e 37²1’22.9” O.

A vegetação nativa predominante na região da área de estudo é classificada pelo Instituto Brasileiro de Geografia e Estatística - IBGE (2012) como Savana Estépica arborizada, com estrato superior arbustivo-arbóreo e um estrato inferior gramíneo-lenhoso. As plantas são adaptadas ao ambiente de altas temperaturas, às irregularidades das precipitações e à baixa umidade relativa do ar. 
Conforme os critérios propostos por Köppen (1996) e descritos por Alvares et al. (2013), o clima regional onde o município está situado é do tipo BSh, onde predomina uma temperatura média de $26,5^{\circ} \mathrm{C}$, com mínima em julho $\left(25,2^{\circ} \mathrm{C}\right)$ e máxima em dezembro $\left(27,7^{\circ} \mathrm{C}\right)$. Em termos pluviométricos, ocorre uma média anual $794 \mathrm{~mm}$, no qual o período de janeiro a maio corresponde $86 \%$ do total acumulado (Alvares et al. 2013).

Os principais tipos de solos constatados na área da propriedade são: Latossolo Vermelho Amarelo Eutrófico e o Cambissolo Eutrófico, predominando dentro do povoamento de Mimosa caesalpiniifolia Benth. o tipo Cambissolo Eutrófico.

O povoamento possui espaçamento 3,0 x 2,5 m, com uma área aproximada de 3 ha, compreendendo na sua totalidade cerca de 4000 indivíduos. As plantas são de reprodução via seminífera e as mudas foram transplantadas para o campo aos 4 meses de idade.

\section{Medidas dendrométricas e cubagem}

Selecionamos 20 indivíduos adultos de forma aleatória e mensuramos os principais parâmetros dendrométricos, conforme detalhados abaixo. O número de indivíduos ficou limitado a 20, principalmente pelos seguintes motivos: a) os indivíduos do povoamento eram bastante homogêneos em campo, em termos de estrutura e tamanho; b) em vista do grande número de medidas dendrométricas que teriam que ser realizadas, como os trabalhos de determinação da biomassa úmida acima do solo e cubagem dos volumes.

Os indivíduos mensurados foram agrupados em três classes de DAP, cuja amplitude foi de 1,5 $\mathrm{cm}$, iniciando com indivíduos com DAP maior que $5,2 \mathrm{~cm}$, sendo estabelecidas as classes de DAP a seguir: 1) $5,2-6,7 \mathrm{~cm}$; 2) $6,7-8,2 \mathrm{~cm} \mathrm{e} \mathrm{3)}>8,2 \mathrm{~cm}$.

Em relação à altura, consideramos a divisão do indivíduo em três segmentos: comprimento da altura total (altura comercial + altura da ponta), comprimento da altura comercial (altura até início da formação da ponta) e comprimento da ponta. A altura da ponta foi considerada como sendo a altura a partir da qual ocorria a formação das copas.

Já em relação à medição dos diâmetros, consideramos a divisão dos indivíduos em três segmentos: diâmetro do toco - DT (medido a 0,2 m a partir do solo), diâmetro medido à altura de 1,3 $\mathrm{m}$ a partir do solo - DAP e diâmetro da ponta - DP (medida a partir do término da altura comercial de cada fuste).

Para a cubagem rigorosa, o corte foi efetuado a $0,2 \mathrm{~m}$ do solo, com utilização de motosserra. Para a determinação do volume com casca $\left(\mathrm{m}^{3}\right)$, foi empregada a metodologia analítica, por meio do procedimento de Smalian (Husch et al. 1972). Para o cálculo do volume à altura comercial e total, mensuramos seções de fustes e ramos com mais de $2 \mathrm{~cm}$ de diâmetro, considerando como $1 \mathrm{~m} \mathrm{o}$ comprimento dos fustes, enquanto o comprimento dos ramos variou em função das medidas de cada ramo que seria cubado em campo. As expressões abaixo resumem os procedimentos adotados para o cálculo dos volumes e dada área seccional (AS), conforme os procedimentos expressos na equação 1, descritos por Soares et al. (2006).

$$
V=\left(\frac{A S_{1}+A S_{2}}{2}\right) * L ; A S=\left(\frac{\text { Diâmetro da seção }^{2} * \pi}{40000}\right)
$$


Em que: $\mathrm{V}=$ volume da seção $\left(\mathrm{m}^{3}\right) ; \mathrm{L}=$ comprimento da seção $(\mathrm{m})-1 \mathrm{~m}$ quando fustes foram cubados e variável quando os ramos foram cubados; $\mathrm{AS}_{1}$ e $\mathrm{AS}_{2}=$ áreas seccionais com casca $\left(\mathrm{m}^{2}\right)$, obtidas na extremidade de cada seção. $O$ diâmetro da seção foi inserida na fórmula em $\mathrm{cm}$. O volume do toco foi calculado com base no diâmetro do toco $(\mathrm{cm})$ e no comprimento do toco $(\mathrm{m})$, segundo a equação 2:

$$
\text { Volume do toco }\left(m^{3}\right)=\left(\frac{\text { Diâmetro do toco }{ }^{2} * \pi}{40000}\right) * L
$$

Em que L é o comprimento do toco em metros (adotamos 0,2 $\mathrm{m}$ como o comprimento para mediação do diâmetro do toco).

Calculamos o volume da ponta considerando que apenas $1 / 3$ do volume real era ocupado por material lenhoso, tendo em vista que o volume da ponta é calculado levando em conta que a figura geométrica que mais se assemelha à ponteira é um cone e, por isso, a fórmula usada para calcular o volume é multiplicado por 1/3. Para isso, obtivemos o volume conforme a equação 3 :

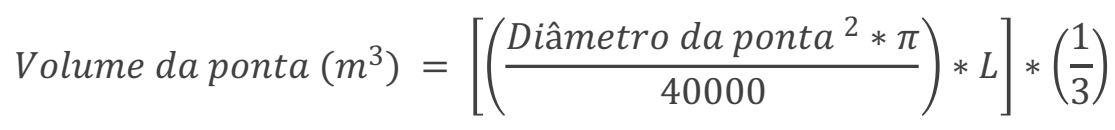

O volume de cada árvore foi separado em volume até altura comercial, volume da ponta, volume do toco e volume total, que foi obtido pelo somatório do volume comercial acrescidos dos volumes da ponta e do toco que permaneceu no solo. Entretanto, só apresentamos nos resultados os volumes à altura comercial e à altura total, em vista da menor importância dendrométrica dos volumes da ponta e do toco para o propósito de ajustes de equações alométricas específicas.

Para obter as medidas da área de projeção da copa - APC $\left(\mathrm{m}^{2}\right)$, foram medidos os diâmetros das copas, em metros, e as áreas foram calculadas utilizando uma fórmula que projeta uma forma circular, segundo a equação 4:

$$
A P C=\frac{\left(\text { Diâmetro da copa }{ }^{2} * \pi\right)}{4}
$$

Esses parâmetros foram calculados visando caracterizar o desenvolvimento espacial dos indivíduos, com a finalidade de inferir informações a respeito do crescimento e da produtividade da espécie no sítio avaliado.

A medição das alturas foi realizada com régua telescópica de PVC, cuja precisão de medição foi de 0,1 m. As circunferências foram medidas com fita diamétrica, com precisão de $0,1 \mathrm{~cm}$.

\section{Quantificação da biomassa aérea úmida}

A determinação da biomassa aérea foi realizada por meio da quantificação da massa úmida total dos seguintes constituintes de cada um dos 20 indivíduos mensurados aleatoriamente: folhas, ramos com diâmetro menor que $2 \mathrm{~cm}$, galhos com diâmetro maior que $2 \mathrm{~cm}$ e fustes. A mediação foi feita em campo, com utilização de uma balança digital de gancho, com capacidade para $50 \mathrm{Kg}$ e precisão de duas casas decimais. 


\section{Modelos para estimativa da biomassa úmida da parte aérea e do volume de madeira}

Para estimar a biomassa aérea total úmida por indivíduo, foram utilizados modelos de regressão, nos quais o DAP e a altura total foram utilizados como variáveis preditoras, de acordo com as exigências de cada modelo matemático. Para isso, usamos, dentre os modelos apresentados por Herrera (1989), Sampaio e Silva (2005), Silva e Sampaio (2008) os listados no quadro 1.

Quadro 1 - Modelos utilizados para ajustar equações alométricas para estimar a biomassa aérea úmida de indivíduos de Mimosa caesalpiniifolia (Benth), aos 12 anos de idade em Mossoró, Rio Grande do Norte,

Brasil

\begin{tabular}{|c|c|c|c|}
\hline Número & Modelo & Número & Modelo \\
\hline 1 & Biomassa $=\beta_{0}+\beta_{1}{ }^{*} \mathrm{DAP}+\varepsilon$ & 6 & $\operatorname{LnBiomassa}=\beta_{0}+(\mathrm{LnDAP})^{\star} \beta_{1}+\varepsilon$ \\
2 & Biomassa $=\beta_{0}+\beta_{1}{ }^{*}\left(\mathrm{DAP}{ }^{2} . \mathrm{Ht}\right)+\varepsilon$ & 7 & LnBiomassa $=\beta_{0}+(\mathrm{LnDAP})^{\star} \beta_{1}+(\mathrm{LnHt})^{\star} \beta_{2}+\varepsilon$ \\
3 & Biomassa $=\beta_{0}+\beta_{1}{ }^{\star}(\mathrm{DAP} . \mathrm{Ht})+\varepsilon$ & 8 & $\operatorname{LnBiomassa}=\beta_{0}+\operatorname{Ln}\left(\mathrm{DAP} \mathrm{Ht}^{\star} \beta_{1}+\varepsilon\right.$ \\
4 & Biomassa $=\beta_{0}+\beta_{1}{ }^{*} \mathrm{DAP}^{2}+\varepsilon$ & 9 & $\operatorname{LnBiomassa}=\beta_{0}{ }^{\star} \operatorname{Ln}\left(\mathrm{DAP}{ }^{2 \star} \mathrm{Ht}^{\star} \beta_{1}+\varepsilon\right.$ \\
5 & LnBiomassa $=\beta_{0}+\operatorname{Ln}\left(\mathrm{DAP}^{2}\right)^{\star} \beta_{1}+\varepsilon$ & & \\
\hline
\end{tabular}

Para estimar o volume individual à altura comercial e à altura total, empregamos modelos de regressão, nos quais utilizamos como variáveis preditoras o DAP e a altura comercial e total dos indivíduos, respectivamente. Foram utilizados os modelos apresentados por Shumache e Hall (1933) e Campos e Leite (2002), conforme quadro 2.

Quadro 2 - Modelos utilizados para ajustar equações alométricas para estimar o volume lenhoso de indivíduos de Mimosa caesalpiniifolia (Benth), aos 12 anos de idade em Mossoró, Rio Grande do Norte, Brasil

\begin{tabular}{|c|c|c|c|}
\hline Número & & Número & Modelo \\
\hline 1 & $\mathrm{~V}=\beta_{0}+\beta_{1}{ }^{*}(\mathrm{DAP})+\varepsilon$ & 4 & $\mathrm{LnV}=\beta_{0}+\left(\mathrm{LnDAP}^{\star} \beta_{1}\right)+\left(\mathrm{LnH}^{\star} \beta_{2}\right)+\varepsilon$ \\
2 & $\mathrm{~V}=\beta_{0}+\beta_{1}{ }^{*}(\mathrm{DAP})^{2}+\varepsilon$ & 5 & $\mathrm{~V}=\beta_{0}+\left(\beta_{1}{ }^{*} \mathrm{DAP}\right)+\left(\beta_{2}{ }^{*} \mathrm{DAP}^{2}\right)+\varepsilon$ \\
3 & $\mathrm{~V}=\beta_{0}+\beta_{1}{ }^{*}\left(\mathrm{DAP}{ }^{2 *} \mathrm{H}\right)+\varepsilon$ & 6 & $\mathrm{LnV}=\beta_{0}+\mathrm{LnDAP}^{\star} \beta 1+\varepsilon$ \\
\hline
\end{tabular}

A avaliação dos modelos para predição do volume e da biomassa total aérea úmida levou em consideração a análise de variância do ajuste (ANOVA com $\mathrm{p}<0,05$ ), a significância dos parâmetros $\beta_{0} \beta_{1}$ e $\beta_{2}$ por meio do teste $\mathrm{F}$, o coeficiente de determinação $\mathrm{R}^{2}$ ajustado pelos graus de liberdade $\left(\mathrm{R}^{2 a j u s}\right)$, a normalidade da distribuição dos resíduos pelo teste de Shapiro-Wilk (W) e o erro-padrão da estimativa em porcentagem $-\mathrm{S}_{\mathrm{yx} \%}$ (Araújo et al. 2004; Soares et al. 2006; Thomas et al. 2006; De Miranda et al. 2011; Soares et al. 2011; Brianezi et al. 2013; Dalla Lana et al. 2018). 
O erro padrão da estimativa foi calculado conforme as equações 5 e 6 (De Miranda et al. 2011; Soares et al. 2011; Brianezi et al. 2013; Dalla Lana et al. 2018).

$$
S y x=\sqrt{\sum_{i=1}^{n} \frac{(y-\hat{y})^{2}}{(n-p-1)}}
$$

$$
\operatorname{Syx}(\%)=\left(\frac{\operatorname{Syx}}{\overline{\mathrm{y}}}\right) * 100
$$

Onde: $\mathrm{Y}=$ valor observado; $\hat{\mathrm{y}}=$ valor estimado; $\mathrm{p}=$ número de parâmetros da equação; $\mathrm{n}=$ número de observações; $\overline{\mathrm{Y}}=$ média observada.

Embora, geralmente, a seleção do melhor modelo seja baseada na escolha daquele que apresenta maior $\mathrm{R}^{2}$, cujo valor expressa a quantidade de variação total que é explicada pela regressão estatística, de tal modo que quanto mais próximo de 1 for o seu valor melhor o ajuste da equação (Sampaio e Silva 2005; Sampaio et al. 2010; Ribeiro Júnior 2013), avaliamos também a distribuição gráfica dos resíduos produzidos pelo modelo, o que indica a dispersão entre os valores estimados e os reais (De Lima et al. 2017; Barreto et al. 2018; Dalla Lana et al. 2018). Apenas os modelos em que a análise de variância do ajuste foi significativa e que os resíduos produzidos tiveram distribuição normal foram apresentados nos resultados e discussão.

\section{Densidade básica}

Dos 20 indivíduos cubados, coletamos discos a 0 (10 cm do solo), 25, 50, 75 e 100\% da altura comercial do fuste. Depois de coletados, acondicionamos os discos em sacos plásticos e os levamos para o Laboratório de Tecnologia da Madeira da UFERSA, campus de Mossoró/RN, onde foram imersos em água em um dessecador até a saturação do volume. Após a saturação, medimos o volume de cada disco pelo método de imersão hidrostática (Vital 1984). Posteriormente, secamos os discos em uma estufa de circulação forçada de ar a $103 \pm 2{ }^{\circ} \mathrm{C}$ até obtenção da massa seca constante, cuja medição foi realizada subsequentemente em balança com precisão de 0,02 Kg. Para cada disco, a densidade básica foi calculada conforme a equação 7 :

$$
\text { Densidade básica }=\frac{\text { Massa seca }(g)}{\text { volume saturado }\left(\mathrm{cm}^{3}\right)}
$$

\section{Resultados e discussão}

A biomassa aérea úmida média foi de $19,86 \mathrm{~kg}$ por indivíduo, com valores mínimo e máximo de 8,52 e $34,5 \mathrm{~kg}$, respectivamente. Nas três classes de DAP, a biomassa de fustes e de galhos $>2 \mathrm{~cm}$, correspondeu, em média, a 77\% da biomassa aérea total úmida (Figura 1).

Quanto a este aspecto, em estudos realizados em áreas nativas de Caatinga, a biomassa de fustes e galhos correspondeu, em média, a 70\% do total registrado (Sampaio e Silva 2005; Silva e Sampaio 2008). Dalla Lana et al. (2018) constataram, em vegetação nativa de Caatinga em Floresta-PE que, em média, a biomassa de fustes e de galhos maiores variou de $70-75 \%$ da biomassa total. 
Em comparação com as referidas pesquisas, a maior participação da biomassa de fustes e de galhos $>2 \mathrm{~cm}$ registrada neste trabalho reflete a formação da estrutura aérea dos indivíduos semelhante à registrada em áreas naturais, dado que a espécie não foi melhorada geneticamente.

Figura 1. Média de biomassa aérea por indivíduo em $\mathrm{Kg}(\mathrm{A})$ e partição da biomassa entre os componentes folhas, ramos $<2 \mathrm{~cm}$, ramos $>2 \mathrm{~cm}$ e fuste em $\mathrm{Kg}$ (B) de indivíduos de Mimosa caesalpiniifolia (Benth) amostrados em um povoamento aos 12 anos de idade em Mossoró, Rio Grande do Norte, Brasil.

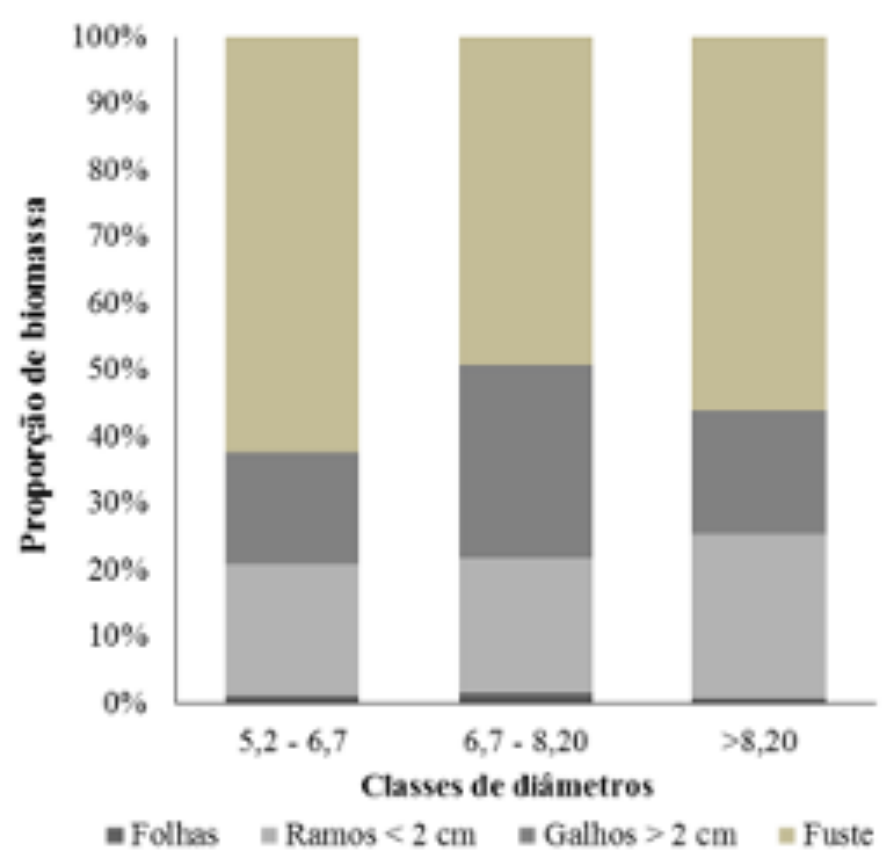

Os valores absolutos de biomassa de ramos $<2 \mathrm{~cm}$ de diâmetro corresponderam à segunda maior quantidade de biomassa nas classes de DAP 1 e 3; porém, em termos percentuais, eles representaram o terceiro constituinte mais importante nessas classes, com exceção da classe II, onde a biomassa de ramos $<2 \mathrm{~cm}$ correspondeu a $29 \%$ da biomassa.

Dessa forma, constatamos que, possivelmente, à medida que os indivíduos incorporam biomassa nos fustes, ocorre, concomitantemente, incremento na formação de galhos, especialmente em classes de DAP $>6,7 \mathrm{~cm}$. Isto é confirmado ao observarmos os valores de área de projeção de copas, que aumentou mais de três vezes da primeira para a terceira classe (Tabela 2 mais adiante). Este fato tem implicação quanto à destinação que se que pode dar à biomassa produzida. Se o objetivo dos povoamentos for a produção de fustes com maiores diâmetros, podas devem ser realizadas para assegurar que a biomassa sintetizada seja realocada para os fustes.

Contudo, experimentos devem ser realizados para averiguar o potencial de ramificação desta espécie após o corte (como as podas), já que as espécies nativas da Caatinga têm alto potencial de brotação após podas ou corte, com aumento significativo do número de ramos quando os fustes são cortados (Ferraz et al. 2014).

Em relação aos modelos para estimar a biomassa aérea úmida, a variável que resultou nos melhores ajustes de estimativa foi o DAP, quando utilizamos equações do tipo linear, destacando-se o modelo 4 (Tabela 1). 
Tabela 1. Parâmetros $\beta_{0}, \beta_{1}$ e $\beta_{2}$, p-valor do teste $\mathrm{F}$ para os parâmetros, intervalo de confiança, valor W e p-valor do teste do Shapiro-Wilk para os resíduos, $\mathrm{R}^{2 \mathrm{aju}}$ e erro padrão da estimativa (\%) referentes aos modelos ajustados para biomassa aérea total úmida de indivíduos de Mimosa caesalpiniifolia (Benth) amostrados em um povoamento aos 12 anos de idade em Mossoró, Rio Grande do Norte, Brasil.

\begin{tabular}{|c|c|c|c|c|c|c|c|}
\hline Modelo & Parâmetro & $\mathrm{p}$-valor/F & $\begin{array}{c}\text { Interv. } \\
\text { parâmetro } \\
-95 \%\end{array}$ & $\begin{array}{l}\text { Interv. } \\
\text { parâmetro } \\
+95 \%\end{array}$ & $\begin{array}{c}\text { W resíduos/ } \\
\text { p-valor }\end{array}$ & $\mathrm{R}^{2 \mathrm{aju}}$ & (Syx \%) \\
\hline 2 & $\begin{array}{c}\beta_{0} \\
10,7689421078359 \\
\beta_{1} \\
0,0254531388907457\end{array}$ & $0,000454^{* *}$ & 5,47847 & 16,05942 & $\begin{array}{c}\mathrm{W}=0,978 \\
\mathrm{p}=0,907\end{array}$ & 0,47 & 26,34 \\
\hline 3 & $\begin{array}{c}\beta_{0} \\
4,44473158992692 \\
\beta_{1} \\
0,340263468468663\end{array}$ & $0,298633^{\mathrm{NS}}$ & $-4,28007$ & 13,16954 & $\begin{array}{c}\mathrm{W}=0,984 \\
\mathrm{p}=0,976\end{array}$ & 0,44 & 27,21 \\
\hline 4 & $\begin{array}{c}\beta_{0} \\
7,134411743986 \\
\beta_{1} \\
0,218501385492548\end{array}$ & $0,000020^{* *}$ & 1,874069 & 12,39475 & $\begin{aligned} \mathrm{W} & =0,923 \\
\mathrm{p} & =0,111\end{aligned}$ & 0,63 & 22,26 \\
\hline 6 & $\begin{array}{c}\beta_{0} \\
-0,119429235115912 \\
\beta_{1} \\
1,52795422593096\end{array}$ & $0,793035^{\mathrm{NS}}$ & $-1,06164$ & $\begin{array}{l}0,822784 \\
1,995323\end{array}$ & $\begin{array}{c}\mathrm{W}=0,938 \\
\mathrm{p}=0,217\end{array}$ & 0,71 & 13,65 \\
\hline 8 & $\begin{array}{c}\beta_{0} \\
-1,05853015873944 \\
\beta_{1} \\
1,0519961028668\end{array}$ & $0,279834^{\mathrm{NS}}$ & $-3,05441$ & 0,937353 & $\begin{aligned} \mathrm{W} & =0,956 \\
\mathrm{p} & =0,468\end{aligned}$ & 0,47 & 28,67 \\
\hline 9 & $\begin{array}{c}\beta_{0} \\
-0,656609235430521 \\
\beta_{1} \\
0,620604392547232\end{array}$ & $0,292626^{\mathrm{NS}}$ & $-1,92907$ & 0,615854 & $\begin{array}{c}\mathrm{W}=0,934 \\
\mathrm{p}=0,185\end{array}$ & 0,64 & 25,22 \\
\hline
\end{tabular}

* Significativo a $5 \%(\mathrm{p}<0,05) ;{ }^{* *}$ Significativo a $1 \%(\mathrm{p}<0,01)$; NS não significativo

Em relação à forma do modelo (linear, potência, exponencial), ainda que a literatura tenha demonstrado que melhores ajustes já tenham sido obtidos por meio de modelos quadráticos ou potência (Sampaio e Silva 2005; Silva e Sampaio 2008; De Lima et al. 2017), eles são poucos superiores em relação modelos lineares, quando ambos são significativos (Sampaio et al. 2010).

Embora os modelos 6 e 9 tenham apresentado um melhor $\mathrm{R}^{2}$ ajustado e menor erro padrão residual da estimativa que o modelo 4 , eles subestimaram, em média, a biomassa individual. A comparação gráfica da distribuição dos resíduos fornece um panorama do melhor ajuste fornecido pelo modelo 4. É importante afirmar que, embora os modelos 6 e 9 tenham fornecido melhores ajustes $\left(R^{2}\right)$ e menores erros padrão da estimativa em relação ao modelo 4, eles produziram resíduos que não apresentavam uma distribuição normal pelo teste de Shapiro-Wilk, a exemplo das equações 1, 5 e 7 (Figura 2). 
Figura 2. Valor de W do teste de Shapiro-Wilk, distribuição gráfica dos resíduos e a dispersão entre os valores estimados e os reais produzidos pelos modelos 4 (A), 6 (B) e 9 (C) ajustados para biomassa aérea total úmida de indivíduos de Mimosa caesalpiniifolia (Benth) amostrados em um povoamento aos 12 anos de idade em Mossoró, Rio Grande do Norte, Brasil.
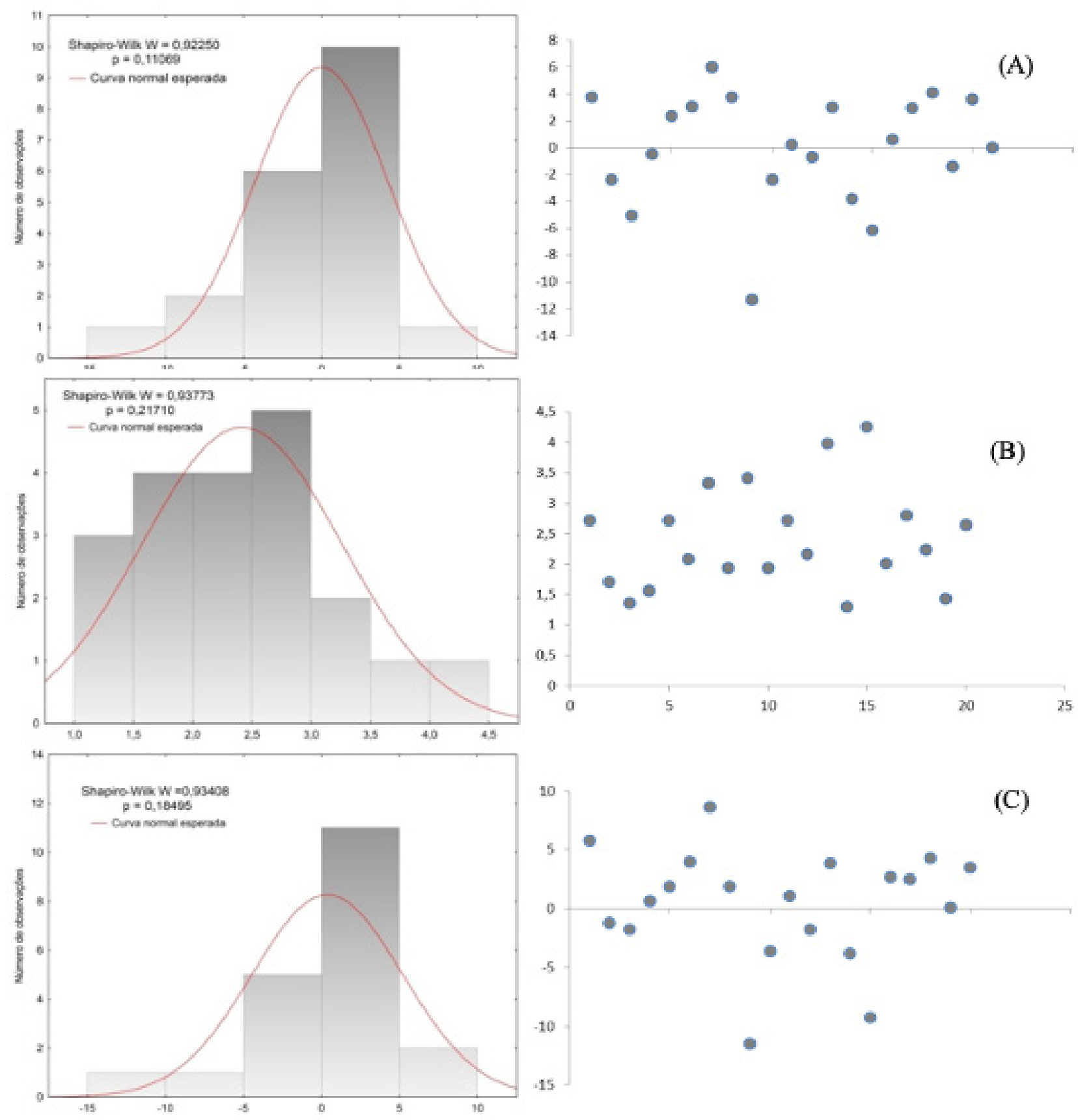

O modelo 6 propiciou subestimativas para todos os valores de DAP fornecidos, enquanto que, de modo geral, o modelo 9 produziu subestimativas importantes para DAPs no intervalo 7-9,5 cm, enquanto superestimavas foram constatadas em DAPs menores $>9,5 \mathrm{e}<6 \mathrm{~cm}$. As estimativas de biomassa produzidas pelo modelo 4 superestimaram, de modo geral, a biomassa para DAPs maiores que 9,2 cm e menores que 6,2, mas a diferenças entre o somatório dos valores observados e previstos variou minimamente, já que foi balanceado pelas subestimativas dos valores de biomassa para os 
DAP que estavam no intervalo entre 6,2 e 9,2. Assim, apesar dessa aparente exatidão, para valores fora do intervalo de DAP citado antes $(6,2-9,2 \mathrm{~cm})$, as estimativas devem produzir maiores erros. As superestimavas registradas para DAPs fora do intervalo 6,2-9,2 cm se deu em função do baixo número de indivíduos registrados nesse intervalo, de modo que a sub-representação de plantas nesse intervalo de DAP representou um fator que pode ter introduzido imprecisões nos modelos. Dessa forma, o seu uso deve considerar essa limitação.

Os erros obtidos com o uso de modelos no formato de potência linearizados $(5,6,7,8$ e 9) produziram subestimativas nos valores de biomassa. Nesse sentido, Sampaio e Silva (2005) afirmam que, nas equações de potência, qualquer pequena alteração no parâmetro exponencial tem um grande efeito sobre a estimativa da biomassa, especialmente em plantas com grandes diâmetros.

Em nenhum dos modelos, a adição da altura total em combinação com o DAP resultou em melhorias significativas dos ajustes. Assim, conforme constatado em outros trabalhos realizados com espécies da Caatinga, a adição de outras variáveis aos modelos embora tenham melhorado os ajustes dos modelos (Sampaio e Silva 2005; Silva e Sampaio 2008; Sampaio et al. 2010), proporcionou ganhos foram pequenos, o que justifica utilizar somente o DAP como variável preditora, tendo em vista a maior facilidade da medição desse atributo em campo e as dificuldades das medições da altura total.

Contudo, quando comparamos os $\mathrm{R}^{2}$ ajustados obtidos pelas equações calculadas neste trabalho com outras pesquisas na Caatinga (Sampaio e Silva 2005; Silva e Sampaio 2008; Sampaio et al. 2010; Dalla Lana et al. 2018; Barreto et al. 2018), constatamos que os nossos melhores ajustes foram inferiores aos calculados por aqueles autores.

Quanto a essas divergências, é preciso salientar que, diferentes dos autores mencionados, optamos por considerar o $\mathrm{R}^{2}$ ajustado pelos graus de liberdade, conforme recomendam Bussab e Morettin (2017). Essa forma de cálculo de coeficiente de determinação ajustado resulta em menores valores de $\mathrm{R}^{2}$. Outro motivo é a variabilidade da biomassa aérea registrada entre os indivíduos avaliados nesta pesquisa (Desvio padrão de 7,38 kg e CV de 37\%).

Dos modelos ajustados, as equações 4, 6 e 9 forneceram os melhores ajustes para todos os parâmetros avaliados. Contudo, quando comparamos os $\mathrm{R}^{2}$ ajustados, vemos que o ganho proporcionado pela medição da altura total para alimentar o modelo 9 não compensa o esforço das operações de campo, uma vez que os $\mathrm{R}^{2}$ ajustados variaram pouco. Além do mais, esse modelo apresentou um maior erro padrão da estimativa.

Em geral, baixos $\mathrm{R}^{2}$ ajustados deve-se às grandes variações da forma dos fustes, da altura, número e comprimento dos galhos dos indivíduos mensurados, de forma que um aumento na intensidade de amostragem não necessariamente melhora a acuracidade dos modelos (Dalla Lana et al. 2018). Os erros das estimativas produzidos pelos modelos estão dentro do intervalo considerado razoável para a maioria dos modelos utilizados para estimar a biomassa de vegetação nativa na Caatinga (25-40\%), e de acordo com o erro produzido em outras pesquisas realizadas na Caatinga (Barreto et al. 2018).

Embora o povoamento apresentasse, à época do estudo, 12 anos, os volumes médios e as alturas totais médias (Tabela 2), nas três classes de DAP, foram menores que os registrados por Barros et al. (2010), em povoamentos de Sabiá com 6,5 anos (os valores médios de volume foram 0,0343 m3 por 
indivíduo). Semelhantemente, as alturas médias registradas neste trabalho foram menores que as registradas por Barros et al. (2010), que constataram uma média de 8,11 m.

Uma explicação razoável para essa discrepância são as diferenças climáticas entre os locais comparados e a satisfação das exigências hídricas e nutricionais da espécie, além de que também maiores densidades de indivíduos podem colaborar para essas diferenças, em função da competição por recursos (Sampaio e Silva 2005).

Tabela 2. Média e desvio padrão (DesvPad) do volume comercial e total, altura total (HT), altura comercial (HC), área de projeção de copas (APC) e área seccional de indivíduos de Mimosa caesalpiniifolia (Benth) amostrados em um povoamento aos 12 anos de idade em Mossoró, Rio Grande do Norte, Brasil.

\begin{tabular}{|c|c|c|c|c|c|c|}
\hline Valores & $\begin{array}{c}\text { Volume } \\
\text { H comercial } \\
\left(\mathrm{m}^{3}\right)\end{array}$ & $\begin{array}{c}\text { Volume } \\
\mathrm{H} \text { total } \\
\left(\mathrm{m}^{3}\right)\end{array}$ & $\begin{array}{l}\text { HT } \\
(\mathrm{m})\end{array}$ & $\begin{array}{l}\mathrm{HC} \\
(\mathrm{m})\end{array}$ & $\begin{array}{l}\text { APC } \\
\left(\mathrm{m}^{2}\right)\end{array}$ & $\begin{array}{c}\text { Área } \\
\text { seccional } \\
\left(\mathrm{m}^{2}\right)\end{array}$ \\
\hline \multicolumn{7}{|c|}{ Classe de DAP 1: 5,2 - 6,7 cm (7 indivíduos) } \\
\hline Média & 0,00892936 & 0,01060655 & 5,94 & 3,81 & 3,36 & 0,00281 \\
\hline DesvPad & 0,0027 & 0,0027 & 1,0783 & 0,7988 & 1,7894 & 0,0006 \\
\hline \multicolumn{7}{|c|}{ Classe de DAP 2: 6,7 - 8,20 cm (5 indivíduos) } \\
\hline Média & 0,010417228 & 0,012197257 & 5,96 & 3,74 & 6,87 & 0,00419 \\
\hline DesvPad & 0,0027 & 0,0028 & 0,6400 & 0,6200 & 3,6700 & 0,0006 \\
\hline \multicolumn{7}{|c|}{ Classe de DAP 3: $>8,20 \mathrm{~cm}$ (8 indivíduos) } \\
\hline Média & 0,01685702 & 0,019238185 & 6,26 & 4,39 & 10,60 & 0,00675 \\
\hline DesvPad & 0,0049 & 0,0057 & 0,8175 & 0,7453 & 5,7497 & 0,0016 \\
\hline
\end{tabular}

Em relação à estrutura espacial dos indivíduos mensurados, observamos que mesmo havendo aumento das alturas totais médias em função da classe de DAP (o que é esperado), esse crescimento foi resultado principalmente do incremento das copas dos indivíduos, o que pode ser constatado pelos valores de área de projeção de copa e pelo baixo incremento das alturas comerciais em função da classe de DAP. Isso implica que, possivelmente, práticas de manejo devem pesquisadas e aplicadas visando uma maior eficiência do crescimento dos fustes, porque as copas são formadas por ramos espaçados de pequenos diâmetros. Como resultado disso, constatamos que os volumes à altura comercial e total não foram tão discrepantes, ainda que as diferenças médias entre as alturas comerciais e totais tenham sido importantes nas três classes de diâmetro. Quanto aos modelos para estimar os volumes à altura comercial e à altura total, os melhores ajustes foram constatados com o uso dos modelos 3 e 4 (Tabela 3). 
Tabela 3. Parâmetros $\beta_{0}, \beta_{1}$ e $\beta_{2}$, p-valor do teste F para os parâmetros, intervalo de confiança, valor W e p-valor do teste do Shapiro-Wilk para os resíduos, $\mathrm{R}^{2}$ aju e erro padrão da estimativa (\%) referentes aos modelos ajustados para à altura comercial e à altura total de indivíduos de Mimosa caesalpiniifolia (Benth) amostrados em um povoamento aos 12 anos de idade em Mossoró, Rio Grande do Norte, Brasil

\begin{tabular}{|c|c|c|c|c|c|c|c|}
\hline \multicolumn{8}{|c|}{ Modelos para estimar o volume à altura comercial } \\
\hline Modelo & Parâmetro & $\begin{array}{l}\mathrm{p} \text {-valor do } \\
\text { teste } \mathrm{F}\end{array}$ & $\begin{array}{l}\text { Interv.Conf. } \\
\text { parâmetros } \\
-95 \%\end{array}$ & $\begin{array}{l}\text { Interv.Conf. } \\
\text { parâmetros } \\
+95 \%\end{array}$ & $\begin{array}{l}\text { Valor W } \\
\text { do teste de } \\
\text { Shapiro- } \\
\text { Wilk e } \\
\text { p-valor }\end{array}$ & $\mathrm{R}^{2 \mathrm{aju}}$ & (Syx) \% \\
\hline 1 & $\begin{array}{c}\beta_{0} \\
-0,00956683371674021 \\
\beta_{1} \\
0,002903071362176\end{array}$ & $0,000374^{* *}$ & $-0,014173$ & $-0,004961$ & $\begin{array}{c}\mathrm{W}=0,954 \\
\mathrm{p}=0,427\end{array}$ & 0,85 & 16,71 \\
\hline 2 & $\begin{array}{c}\beta_{0} \\
0,00134027430973998 \\
\beta_{1} \\
0,00018491108166662\end{array}$ & $0,202273^{\mathrm{NS}}$ & $-0,000787$ & 0,003468 & $\begin{aligned} W & =0,979 \\
\mathrm{p} & =0,921\end{aligned}$ & 0,88 & 14,65 \\
\hline 3 & $\begin{array}{c}\beta_{1} \\
0,0000322813042346465\end{array}$ & $0,000000^{* *}$ & 0,000029 & 0,005361 & $\begin{array}{c}\mathrm{W}=0,974 \\
\mathrm{p}=0,837\end{array}$ & 0,94 & 9,99 \\
\hline \multirow{3}{*}{4} & $\begin{array}{c}\beta_{0} \\
-8,06567161511698\end{array}$ & $0,000000^{* *}$ & $-8,60324$ & $-7,52811$ & \multirow{3}{*}{$\begin{aligned} W & =0,965 \\
p & =0,656\end{aligned}$} & \multirow{3}{*}{0,91} & \multirow{3}{*}{9,86} \\
\hline & $\begin{array}{c}\beta_{1} \\
1,23928700933934\end{array}$ & $0,000000^{* *}$ & 0,90625 & 1,57232 & & & \\
\hline & $\begin{array}{c}\mathrm{B}_{2} \\
0,815023606980982\end{array}$ & $0,000000^{* *}$ & 0,43422 & 1,19583 & & & \\
\hline \multirow{3}{*}{5} & $\begin{array}{c}\beta_{0} \\
0,0142562757331717\end{array}$ & $0,114445^{\mathrm{NS}}$ & $-0,003820$ & 0,032333 & \multirow{3}{*}{$\begin{aligned} W & =0,980 \\
p & =0,933\end{aligned}$} & \multirow{3}{*}{0,89} & \multirow{3}{*}{14,17} \\
\hline & $\begin{array}{c}\beta_{1} \\
-0,00335248209770382\end{array}$ & $0,147533^{\mathrm{NS}}$ & $-0,008014$ & 0,001309 & & & \\
\hline & $\begin{array}{c}\mathrm{B}_{2} \\
0,000393125078260562\end{array}$ & $0,011116^{*}$ & 0,000102 & 0,000684 & & & \\
\hline \multirow{3}{*}{6} & $\begin{array}{c}\beta_{0} \\
-7,83171270065012\end{array}$ & $0,000000^{* *}$ & $-8,58710$ & $-7,07632$ & \multirow{3}{*}{$\begin{aligned} W & =0,957 \\
\mathrm{p} & =0,486\end{aligned}$} & \multirow{3}{*}{0,82} & \multirow{3}{*}{15,53} \\
\hline & $\begin{array}{c}\beta_{1} \\
1,68181864687152\end{array}$ & $0,000000^{* *}$ & 1,30712 & 2,05652 & & & \\
\hline & $\begin{array}{c}\beta_{1} \\
0,671773089781666\end{array}$ & $0,000000^{\star *}$ & 0,57396 & 0,76959 & & & \\
\hline
\end{tabular}


Modelos para estimar o volume à altura total

\begin{tabular}{|c|c|c|c|c|c|c|c|}
\hline 1 & $\begin{array}{c}\beta_{0} \\
-0,00968664449512484 \\
\beta_{1} \\
0,00318025600026254\end{array}$ & $0,00127^{\star *}$ & $-0,015022$ & $-0,004351$ & $\begin{array}{c}W=0,967 \\
p=0,693\end{array}$ & 0,83 & 16,70 \\
\hline 2 & $\begin{array}{c}\beta_{0} \\
0,00220869365360138 \\
\beta_{1} \\
0,000203449674732813\end{array}$ & $0,071979^{\mathrm{NS}}$ & $-0,000219$ & 0,004636 & $\begin{aligned} W & =0,968 \\
\mathrm{p} & =0,722\end{aligned}$ & 0,84 & 14,42 \\
\hline 3 & $\begin{array}{c}\beta 0 \\
0,00404929514539746 \\
\beta 1 \\
0,0000278267926885885\end{array}$ & $0,000009^{\star *}$ & 0,002662 & 0,005437 & $\begin{aligned} W & =0,957 \\
\mathrm{p} & =0,478\end{aligned}$ & 0,94 & 9,69 \\
\hline \multirow{3}{*}{4} & $\begin{array}{c}\beta 0 \\
-8,40127017418086\end{array}$ & $0,000000^{\star *}$ & $-9,16291$ & $-7,63963$ & \multirow{3}{*}{$\begin{aligned} W & =0,967 \\
p & =0,683\end{aligned}$} & \multirow{3}{*}{0,89} & \multirow{3}{*}{11,24} \\
\hline & $\begin{array}{c}\beta 1 \\
1,32489264258883\end{array}$ & $0,000000^{\star *}$ & 1,03173 & 1,61806 & & & \\
\hline & $\begin{array}{c}\text { B2 } \\
0,804897004770928\end{array}$ & $0,001173^{\star *}$ & 0,36854 & 1,24125 & & & \\
\hline \multirow{3}{*}{5} & $\begin{array}{c}\beta 0 \\
0,0209770015681446\end{array}$ & $0,038535^{\star *}$ & 0,001243 & 0,040711 & \multirow{3}{*}{$\begin{aligned} \mathrm{W} & =0,972 \\
\mathrm{p} & =0,802\end{aligned}$} & \multirow{3}{*}{0,89} & \multirow{3}{*}{13,35} \\
\hline & $\begin{array}{c}\beta 1 \\
-0,00487150893104975\end{array}$ & $0,059455 \mathrm{NS}$ & $-0,009960$ & 0,000217 & & & \\
\hline & $\begin{array}{c}\text { B2 } \\
0,00050600650111279\end{array}$ & $0,003731^{\star *}$ & 0,000188 & 0,000824 & & & \\
\hline \multirow{3}{*}{6} & $\begin{array}{c}\beta 0 \\
-7,40710326716446\end{array}$ & $0,000000^{* *}$ & $-8,12324$ & $-6,69097$ & \multirow{3}{*}{$\begin{aligned} W & =0,952 \\
p & =0,397\end{aligned}$} & \multirow{3}{*}{0,81} & \multirow{3}{*}{15,85} \\
\hline & $\begin{array}{c}\beta 1 \\
1,5484360266619\end{array}$ & $0,000000^{\star *}$ & 1,19321 & 1,90366 & & & \\
\hline & $\begin{array}{c}\beta 1 \\
0,68823135340048\end{array}$ & $0,000000^{* *}$ & 0,57760 & 0,79886 & & & \\
\hline
\end{tabular}

${ }^{*}$ Significativo a $5 \%(p<0,05)$; $*$ Significativo a $1 \%(p<0,01)$; NS não significativo 
O modelo 4 produziu tendências de subestimativas mais pronunciadas que o modelo 3 para as duas categorias de volume consideradas. As subestimativas produzidas pelo modelo 4 foram, em média, da ordem de 0,0014 e $0,0023 \mathrm{~m}^{3}$ por indivíduo, para as alturas comerciais e totais, respectivamente.

Os modelos 3 e 4 foram os mais comumente descritos na literatura como os que forneceram os melhores ajustes da estimativa do volume em fitofisionomias na Caatinga (Silva 2005; Thomas et al. 2006; Souza et al. 2016). Embora o modelo 4 (Schumacher e Hall linearizado) tenha propiciado as estimativas mais acuradas em estudos com múltiplas espécies, o modelo 3 (Spurr 1952) forneceu o melhor ajuste para estimativa do volume de uma espécie do gênero Mimosa, ainda que o R2 não tenha sido maior que 0,8 , o que foi atribuído à grande variabilidade da estrutura espacial da espécie, com grande quantidade de ramificações e múltiplos fustes por indivíduo (Araújo et al. 2004).

A variabilidade da estrutura aérea das espécies da Caatinga, com muitas ramificações e fustes não retilíneos, aumenta a variância das medições do volume observado, o que resulta em perdas do poder preditor dos modelos, ainda que haja uma forte relação entre o DAP e o volume observado (Souza et al. 2016; Barreto et al. 2018). Assim, maiores erros são acrescentados aos modelos quando há muita variabilidade em relação aos dados de biomassa e volume cubados que são utilizados para ajustar os modelos (Brianezi et al. 2013).

Ao compararmos os modelos 3 e 4, em relação às duas categorias de volume estudadas, constatamos que os resíduos produzidos pelo modelo 4, apesar de terem distribuição normal tiveram uma distribuição gráfica mais desuniforme que os do modelo 3. Uma possível explicação para esse comportamento é o fato de que a variância dos resíduos produzidos pelo modelo 4 foi maior que a do modelo 3 (Figura 3).

Pequenas superestimativas/subestimativas e heterocidasticidade dos resíduos produzidos pelo modelo 4 também podem ter ocorrido em função da maior sensibilidade desse modelo à variabilidade das variáveis preditoras, a exemplo da complexa variação intrínseca das interações entre DAP e a altura das espécies da Caatinga, o que é um comportamento típico de espécies nativas que não passaram por melhoramento genético (Barreto et al. 2018).

Os melhores ajustes obtidos com o uso do modelo 4 podem ser conseguidos quando são utilizados dados de diâmetro que têm menor variabilidade, como aqueles obtidos na base (DNB a $0,3 \mathrm{~m}$ ), uma vez que espécies da Caatinga apresentaram uma maior variabilidade dos fustes na altura do DAP, tanto em relação à forma quanto aos valores da circunferência de fustes (Silva 2005; Souza et al. 2016). Esse último autor sugere que o uso do diâmetro equivalente pode ser uma alternativa útil para contornar esse tipo de problema em relação a indivíduos com mais de um fuste. 
Figura 3. Valor de W do teste de Shapiro-Wilk, normalidade, distribuição gráfica dos resíduos contendo a dispersão entre os valores estimados e os reais produzidos pelos modelos 3 e 4 ajustados para o volume à altura comercial (A e B) e à altura total (C e D), respectivamente, de indivíduos de Mimosa caesalpiniifolia (Benth) amostrados em um povoamento aos 12 anos de idade em Mossoró, Rio Grande do Norte, Brasil

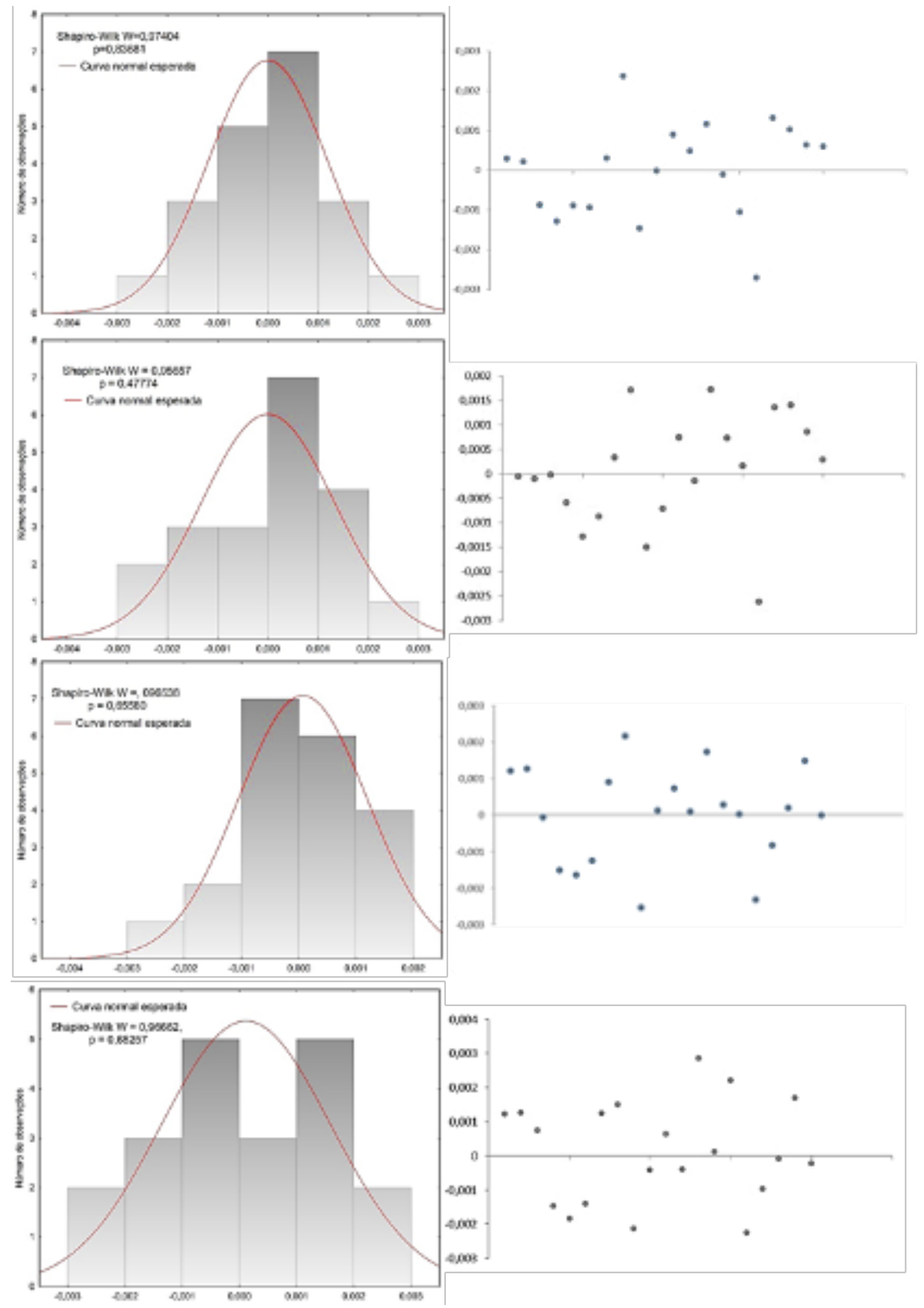


A utilização somente do DAP como variável preditora pode não ser a melhor alternativa para abastecer os modelos, tendo em vista que as equações nas quais se utilizou somente o DAP, ao contrário dos modelos para estimativa da biomassa aérea úmida, produziram os menores $\mathrm{R}^{2}$ ajustados e os maiores erros das estimativas.

A utilização da altura em modelos preditores de volume é, dessa forma, indispensável, uma vez que o volume dos indivíduos arbóreo-arbustivos depende da interação entre altura DAP e altura. Isso é justificado pelo fato de que árvores com mesmo diâmetro (DAP) podem possuir alturas diferentes e diversas formas dos fustes e, consequentemente, volumes variados (Soares et al. 2011).

Além disso, a baixa relação entre altura e a biomassa aérea seria explicada pela uniformidade das alturas dos indivíduos da Caatinga, cuja pouca variabilidade é influenciada, em termos mais gerais, por condições climáticas e pedológicas (Brianezi et al. 2013; Barreto et al. 2018).

Assim, a baixa variabilidade nas alturas, registradas nos inventários, seria, possivelmente, responsável por uma pequena relação entre a altura e a biomassa aérea das espécies da Caatinga, o que resulta em poucas melhorias nos ajustes dos modelos após a inserção da altura como variável preditora da biomassa, como já ressaltado anteriormente.

Contudo, além dessa possível justificativa, este fato pode ser também explicado pelas relações baseadas na densidade da madeira. Na maior parte, senão a maioria das espécies, o volume resulta de relações dependentes da interação entre áreas seccionais (dependentes do diâmetro) e altura (ou comprimento da seção). Já a biomassa constatada em uma mesma unidade de volume será maior quanto maior for o valor da densidade da madeira considerada.

Assim, no caso da espécie estudada neste trabalho, a menor capacidade preditora da biomassa aérea úmida dos modelos que combinam DAP e altura pode ser justificada, provavelmente, pela maior densidade da madeira constatada em alturas menores que $1,5 \mathrm{~m}$.

Assim, como a densidade decresce, em geral, para menos de $1 \mathrm{gm} \mathrm{cm} 3$ a partir de alturas maiores que $25 \%$ da altura comercial (em média, $>1 \mathrm{~m}$ ), conforme figura 4, os incrementos em altura não são acompanhados linearmente por aumento da biomassa. Provavelmente, por este motivo, a adição da altura como variável preditora da biomassa aérea úmida resultou em pouca melhoria dos ajustes dos modelos avaliados.

Figura 4. Perfil médio da densidade básica de discos da madeira amostrados a 0, 25, 50, 75 e 100\% da altura comercial de indivíduos de Mimosa caesalpiniifolia (Benth) em um povoamento aos 12 anos de idade em Mossoró, Rio Grande do Norte, Brasil

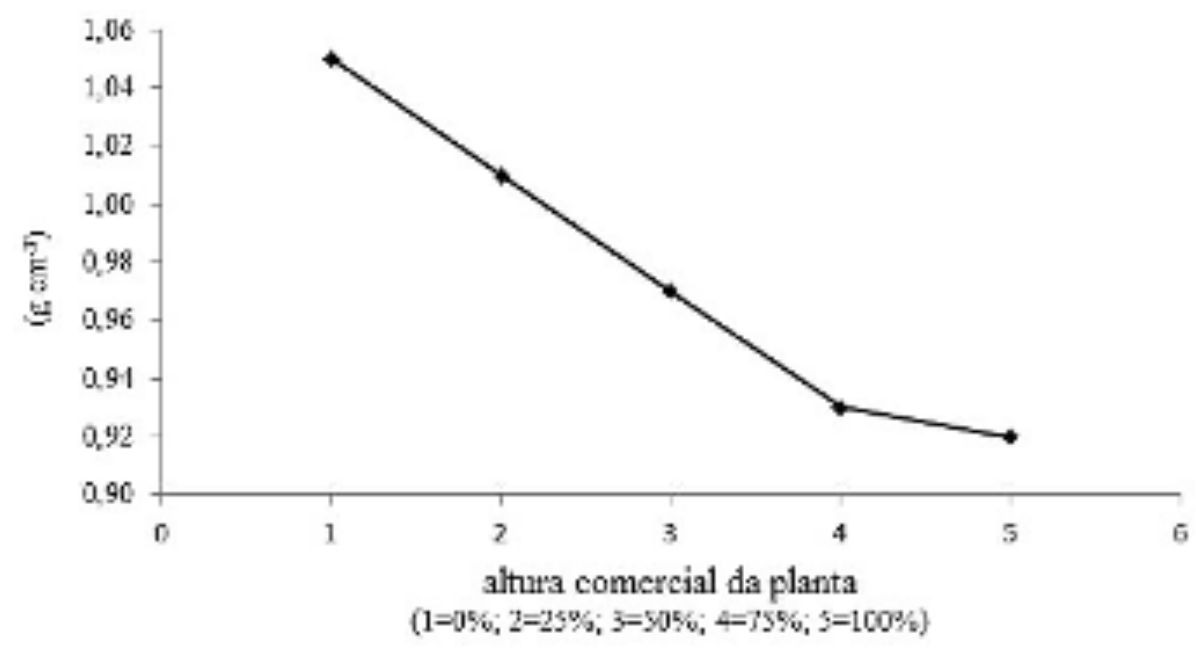


Isso implica que, geralmente, em espécies da Caatinga, o crescimento do volume é mais rápido do que o aumento em densidade da madeira em um mesmo período considerado (Santana 2017), o que pode explicar o fato de a densidade da madeira diminuir nas partes mais altas dos indivíduos arbóreo-arbustivos, de tal modo que a altura não traga melhorias nos ajustes para estimativas da biomassa aérea, mas que é útil nas estimativas de volume.

Este fenômeno é explicado pelo fato de que, em grande parte das espécies da Caatinga, o incremento do volume em relação à densidade só ocorre até determinada idade, a partir da qual ocorre a chamada retração da madeira, que é a idade em que acontece a estabilização do crescimento do volume e um aumento significativo da densidade e poder calorífico (Santana 2017).

\section{Conclusões}

Para as estimativas da biomassa úmida aérea total, o modelo Biomassa $=7,134411743986+$ $0,218501385492548^{\star} \mathrm{DAP}^{2}+\varepsilon$ foi o mais adequado aos dados ajustados aos dados de um povoamento de 12 anos idade.

A biomassa de fustes e de galhos $>2 \mathrm{~cm}$, correspondeu, em média, a 77\% da biomassa aérea total úmida e representou, em média, a mesma proporção nas três classes de DAP.

Os modelos de potência linearizados $(5,6,7,8$ e 9) produziram subestimativas da biomassa úmida aérea total.

Os modelos que forneceram os melhores ajustes para estimar o volume à altura comercial e altura total de um povoamento de 12 anos de idade foram, respectivamente: $\mathrm{V}=0,0042493278498619$ $+0,0000322813042346465^{\star}\left(\mathrm{DAP}^{2 \star}\right.$ Hcomercial $)+\varepsilon$ e $\mathrm{V}=0,00404929514539746+$ $0,0000278267926885885^{\star}\left(\mathrm{DAP}^{2 \star} \mathrm{Htotal}\right)+\varepsilon$.

A altura foi uma variável que contribuiu para a melhoria dos modelos para estimar o volume, enquanto não produziu melhorias nos modelos para estimar a biomassa aérea úmida.

Participação dos autores: MSL - verificação da análise preliminar dos dados, supervisão, correções e adequações da redação inicial do manuscrito, redação final e correções do manuscrito que será publicado; EDGS, RMB - realização de trabalhos de campo, tabulação dos dados de campo, análise preliminar dos dados e redação inicial do manuscrito; ARA - elaboração do projeto de pesquisa, orientação e supervisão dos trabalhos de campo, supervisão da análise preliminar dos dados, redação inicial e correções do manuscrito; ACH, RRM - orientação e supervisão dos trabalhos de campo, supervisão da análise preliminar dos dados, redação inicial e correções do manuscrito.

Aprovação ética e licenças: não se aplica para o tipo de pesquisa realizada.

Disponibilidade dos dados: os dados não estão disponíveis em nenhuma base ou repositores.

Fomento: O presente trabalho foi realizado com apoio da Coordenação de Aperfeiçoamento de Pessoal de Nível Superior - Brasil (CAPES) - Código de Financiamento 001.

Conflito de Interesses: Os autores declaram não haver conflito de interesses com quaisquer instituições ou pesquisadores quanto à publicação dos dados e das conclusões do artigo.

\section{Referências}

Alencar FHH. 2011. Resistência natural da madeira de sabiá (Mimosa Caesalpiniifolia Benth.) a cupins subterrâneos. Revista Caatinga, 24(1): 57-64. 
Alvares CA, Stape JL, Sentelhas PC, Gonçalves JLM, Sparovek G. 2013. Köppen’s climate classification map for Brazil. Meteorologische Zeitschrift, 22(6): 711-728. Doi: http://dx.doi.org/10.1127/0941-2948/2013/0507.

Araújo LVC, Leite JAN, Paes JB. 2004. Estimativa da produção de biomassa de um povoamento de jurema-preta (Mimosa tenuiflora (WILLD.) POIRET. com cinco anos de idade. Biomassa \& Energia, 1(4): 347-352.

Barros BC, Silva JAA, Ferreira RLC, Rebouças ACMN. 2010. Volumetria e sobrevivência de espécies nativas e exóticas no polo gesseiro do Araripe, PE. Ciência Florestal, 20(4): 641-647. Doi: https://doi.org/10.5902/198050982422

Barreto TNA, Silva JAA, Ferreira RLC, Almeida CCS. 2018. Ajuste de modelos matemáticos à biomassa seca dos compartimentos de plantas lenhosas em área de caatinga. Scientia Forestalis, 46 (118): 285-295. Doi: http://dx.doi. org/10.18671/scifor.v46n118.14.

Brianezi D, Jacovine LAG, Soares CPB, Castro RVO, Basso VM. 2013. Equações alométricas para estimativa de carbono em árvores de uma área urbana em Viçosa - MG. Revista Árvore, 37(6): 1073-1081. Doi: http://dx.doi.org/10.1590/ S0100-67622013000600009

Bussab WO, Morettin PA. 2017. Estatística básica. São Paulo: Saraiva, 554p.

Campos JCC, Leite HG. 2002. Mensuração Florestal: perguntas e respostas. Viçosa: Editora UFV, 407 p.

Chave J, Andalo C, Brown, S, Cairns MA, Chambers JQ, Eamus D, Fölster H, Fromard F, Higuchi, N, Kira T. 2005. Tree allometry and improved estimation of carbon stocks and balance in tropical forests. Oecologia, 145(1): 87-99. Doi: http://dx.doi.org/10.1007/s00442-005-0100-x.

Dalla Lana M, Ferreira RLC, Silva JAA, Duda GP, Lins e Silva Brandão CF, Da Silva AF. 2018. Biomass Equations for Caatinga Species. Nativa, 6(5): 517-525. Doi: http://dx.doi.org/10.31413/nativa.v6i5.5361

De Lima RB, Alves Júnior FT, De Oliveira CP, Silva JAA, Ferreira RLC. 2017. Predicting of biomass in Brazilian tropical dry forest: a statistical evaluation of generic equations. Anais da Academia Brasileira de Ciencias, 89(3): 1815-1828. Doi: http://dx.doi.org/10.1590/0001-3765201720170047

De Miranda DLC; De Melo ACG; Sanqueta CR. 2011. Equações alométricas para estimativa de biomassa e carbono em árvores de reflorestamento de restauração. Revista Árvore, 35(3): 679-689. Disponível em: https://doi.org/10.1590/ S0100-67622011000400012.

Ferraz JS F, Ferreira RLC, Silva JAA, Meunier IMJ, Santos MVF. 2014. Estrutura do componente arbustivo-arbóreo da vegetação em duas áreas de Caatinga, no município de Floresta, Pernambuco. Revista Árvore, 38(6):1055-1064. Doi: http://dx.doi.org/10.1590/S0100-67622014000600010

Herrera MEF. 1989. Densidade básica e equações de peso de madeira seca de povoamentos de eucalipto de acordo com a idade, espécie e método de regeneração. Dissertação (Mestrado em Ciência Florestal) - Universidade Federal de Viçosa. Viçosa: UFV. 113f.

Husch B, Miller CI, Beers TW. 1972. Forest mensuration. 3.ed. New York: The Ronald Press, 402 p.

Ibge - Instituto Brasileiro de Geografia e Estatística. 2012. Manual técnico da vegetação Brasileira. Rio de Janeiro: Ibge, 271p.

Köppen W. 1996. Sistema geográfico dos climas. Notas e Comunicado de Geografa - Série B: Textos Didáticos $n^{\circ} 13$. Recife: Editora Universitária UFPE, 31p.

Maia GN. 2012. Caatinga: árvores e arbustos e suas utilidades. 2. ed. Fortaleza: Printcolor Gráfica e Editora, 413 p. il.

Ribeiro Júnior JI. 2013. Análises estatísticas no Excel: guia prático. Viçosa: Editora UFV, 311p.

Schumacher FX, Hall FS. 1933. Logarithmic expression of timber volume. Journal of Agricultural Research, 47(9): 719734. Disponível em: <https://naldc.nal.usda.gov/download/IND43968352/PDF> 
Sampaio EVSB, Silva GC. 2005. Biomass equations for Brazilian semiarid caatinga plants. Acta Botanica Brasilica, 19(4): 935-943. Doi: http://dx.doi.org/10.1590/S0102-33062005000400028

Sampaio EVSB; Gasson P, Baracat A, Cutler D. Pareyn FGC, Lima KC. 2010. Tree biomass estimation in regenerating areas of tropical dry vegetation in northeast Brazil. Forest Ecology and Management, 259(6): 1135-1140. Doi: http:// dx.doi.org/10.1016/j.foreco.2009.12.028

Santana OA. 2017. Minimum age for clear-cutting native species with energetic potential in the Brazilian semi-arid region. Canadian Journal of Forest Research, 47(3): 411-417. Doi: http://dx.doi.org/10.1139/cjfr-2016-0392

Silva JA. 2005. Fitossociologia e relações alométricas em caatinga nos estados da Paraíba e Rio Grande do Norte. Tese (Doutorado em Ciência Florestal) - Universidade Federal de Viçosa. Viçosa: UFV, 93 f.

Silva GC, Sampaio EVSB. 2008. Biomassas de partes aéreas em plantas da caatinga. Revista Árvore, 32(3): 567-575. Doi: https://doi.org/10.1590/S0100-67622008000300017

Spurr SH. 1952. Forest inventory. New York: The Ronald Press Company, 476p.

Soares CPB, Paula Neto F, Souza AL. 2006. Dendrometria e inventário florestal. Viçosa: Ed. UFV, 276p.

Soares CPB, Martins FB, Leite Junior HU, Silva GF, Figueiredo LTM. 2011. Equações hipsométricas, volumétricas e de taper para onze espécies nativas. Revista Árvore, 35(5):1039-1051. Doi: http://dx.doi.org/10.1590/S0100-67622011000600010

Souza PF, Silva JA, Lucena DS, Santos WS, Henriques IGN, Lucena MFA, Souza AD. 2016. Estudos fitossociológicos e dendrométricos em um fragmento de Caatinga, São José de Espinharas-PB. Ciência Florestal, 26(4): 1317-1330. Doi: https://doi.org/10.5902/1980509825152

Thomas C, Andrade CM, Schneider PR, Finger CAG. 2006. Comparação de equações volumétricas ajustadas com dados de cubagem e análise do tronco. Ciência Florestal, 16(3): 319-327. Doi: https://doi.org/10.5902/198050981911

Vital BR. 1984. Métodos de determinação da densidade da madeira. Viçosa: Sociedade de Investigações Florestais, Boletim Técnico 1, 21 p. 